AEA, LXXVI, 2003, 302, pp. 177 a 185. ISSN: 0004-0428

\title{
MANIFIESTOS Y TEXTOS PROGRAMÁTICOS DE LA SOCIEDAD DE ARTISTAS IBÉRICOS
}

\author{
POR \\ JAVIER PÉREZ SEGURA \\ Universidad Complutense de Madrid
}

\begin{abstract}
El arte español de vanguardia se caracterizó por una ausencia casi total de textos teóricos; una de las excepciones más destacadas lo constituye la Sociedad de Artistas Ibéricos (1925-1936), formada por críticos de arte, artistas, escritores... Desde su fundación en 1925, el protagonismo de los críticos de arte produjo un número importante de textos teóricos, que comienzan con el primer manifiesto, en mayo de 1925 . Poco después, la Sociedad de Artistas Ibéricos desaparecía. Habría que esperar a 1931 para que se reanudase la historia de esa agrupación; en otoño consiguen que el nuevo gobierno se interese por ellos y les apoye económicamente. En 1932 publican dos nuevos manifiestos, así como otros textos teóricos que complementan su intensa actividad, que cuenta con hitos como la publicación de su revista, Arte, o la celebración de muestras en Copenhague, Berlín o París.
\end{abstract}

Palabras clave: Pintura española s. xx. Textos y manifiestos. Sociedad Artistas Ibéricos.

The Spanish avant-garde is been characterized by an almost complete absence of theoretical essays; one of the most important exceptions is the Sociedad de Artistas Ibéricos (1925-1936), composed of critics of art, artists, writers... Since its foundation in 1925, the leadership of the critics of art made possible a great number of theoretical essays, which began with the first manifesto, signed in May, 1925. Short after, the Sociedad de Artistas Ibéricos disappeared. It took a long time, till 1931, so that the history of this association could continue. In Fall 1931 they succeeded in attracting the new government, which decided to support them economically. In 1932 they published two new manifestos and some other theroretical texts which complemented their intense activity like, for example, their own magazine or the celebration of exhibitions in Copenhague, Berlin and Paris.

Key words: XX century. Spanish painting. Artistic literature. Artistas Ibéricos Society.

El arte moderno y vanguardista en España es, desde luego, bastante personal en relación con los modelos llamémoslos «canónicos» del resto de Europa. Nuestro arte, situado en la periferia geográfica y cultural de las principales corrientes de la contemporaneidad, comenzó el siglo $\mathrm{xx}$ con un balance muy deficitario - con las excepciones de Barcelona $\mathrm{y}$, en menor medida, Bilbao- que Jaime Brihuega sistematizó en los primeros años ochenta en diversos libros $^{1}$ : discontinuidad de los episodios de vanguardia, tanto en el espacio como en el tiempo; dependencia respecto a los modelos ajenos; escasez de plataformas de difusión, privadas y

1 Brihuega, J.: Las vanguardias artísticas en España, 1909-1936, Madrid, Istmo, 1981; Manifiestos, proclamas, panfletos y textos doctrinales. Las vanguardias artísticas en España, 1910-1936, Madrid, Cátedra, 1982; La vanguardia y la república, Madrid, Cátedra, 1982. 
públicas, para ese arte; debilidad del asociacionismo entre artistas españoles avanzados; escasa consistencia teórica o doctrinal de las actuaciones de índole más moderno. Si bien en los años treinta algunas de estas situaciones empiezan a subsanarse, continúa siendo un modelo compartido entre los especialistas del periodo que el arte español moderno mantuvo esos perfiles de forma invariable ${ }^{2}$.

Con ser esto cierto en líneas generales, las investigaciones de los últimos años han variado drásticamente la realidad de dos apartados concretos, el asociacionismo y el carácter casi ágrafo de nuestra modernidad y vanguardia. Respecto al primero, conocemos con bastante certeza las actuaciones de grupos como los Independientes ${ }^{3}$, la AGAP (Agrupación Gremial de Artistas Plásticos), los Artistas de Acción ${ }^{4}$ o ADLAN (Amigos De Las Artes Nuevas). En cuanto al segundo aspecto, una de las grandes virtudes de los estudios de Jaime Brihuega fue dar a conocer de manera coral cuantos textos se habían publicado entre los años 1909 y 1939. Sin embargo, entonces muchos de ellos parecían desconectados entre sí y la investigación posterior aportaría decenas de otros textos doctrinales.

Cuando en diciembre de 1997 leí mi tesis doctoral sobre las actividades de la Sociedad de Artistas Ibéricos (en adelante, SAI) una de las conclusiones más destacadas, aparte de sus numerosas actuaciones entre 1925 y 1936, fue la existencia de un abundante corpus teórico que origina, respalda, justifica y relaciona toda esa apasionante biografía colectiva ${ }^{5}$.

No es extraño que ese novedoso y sólido componente teórico fuese puesto en relieve ya con motivo de la primera Exposición de la SAI en el Palacio del Retiro:

«La actuación de la Sociedad de Artistas Ibéricos se apoya en conceptos estéticos claramente fijados. Sus teorizantes y críticos los han expuesto en recientes conferencias y manifiestos. Esta base doctrinal permite a la Sociedad una gran soltura de movimiento sin desdecirse de su firme orientación» ${ }^{6}$.

Esta opinión de Julio Álvarez del Vayo era compartida en 1925 por la casi totalidad de quienes se mostraron interesados por la naturaleza de la SAI. Y es que el predominante papel que tuvo la crítica de arte avanzada en su fundación y en sus posteriores actuaciones durante la dictadura y la república hace preciso un análisis con detenimiento de los episodios que definieron aquélla, la formación e intenciones de los diversos críticos de arte y, en última instancia, acerca de cuál fue el armazón intelectual que rigió, desde planteamientos estrictamente estéticos, la trayectoria de la SAI.

\section{La presentación de la SAI a través de sus textos teóricos}

La SAI nacía en febrero o marzo de 1925, pero debía ser entendida en parte como una evolución de la efímera Sociedad de Artistas Españoles (en adelante, SAE), surgida dos años antes y mal conocida todavía por los especialistas en el tema ${ }^{7}$. En el Manifiesto de la SAE se

\footnotetext{
${ }^{2}$ Bozal, V.: Pintura y escultura españolas del s. xx (1900-1939), Summa Artis, t. Madrid, Espasa-Calpe, 1992. Carmona, E.: Picasso, Miró, Dalí y los orígenes del arte contemporáneo en España 1900-1936, Madrid, MNCARS, 1991; Calvo Serraller, F.: «Sísmicos istmos», en Vanguardias españolas 1915-1936 Istmos, Madrid, Caja Madrid, 1998, pp. 11-36; VV.AA. (ed. Harris, D.): The Spanish avant-garde, Manchester University Press, 1994.

${ }^{3}$ García, I.: «López-Obrero y el arte español entre 1925 y 1939», en Cuatro cordobeses en vanguardia. Botí, Ferrer, López-Obrero, Rodríguez Luna, Córdoba, Diputación Provincial, 2000, pp. 124-143.

${ }^{4}$ Pérez Segura, J.: Horacio Ferrer, Córdoba, 2001, pp. 45-49. Sobre AGAP, véase del mismo autor, «Moreno Villa y los emblemas de lo moderno», José Moreno Villa, poesía y pintura, Granada, Huerta de San Vicente, 2000, pp. 15-39.

${ }^{5}$ Pérez Segura, J.: La Sociedad de Artistas Ibéricos (1920-1936), tesis doctoral inédita, Madrid, UCM, 1997. Véase también el catálogo de la exposición La Sociedad de Artistas Ibéricos y el arte español de 1925, Madrid, MNCARS, Bilbao, Museo de Bellas Artes, 1995-1996.

6 Álvarez del Vayo, J.: «La Exposición de Artistas Ibéricos», La Nación, Buenos Aires, 5-VII-1925.

7 Pérez Segura, J.: La Sociedad de... op. cit., capítulo II.1.4., pp. 18-21.
} 
imponen las propuestas —en torno al arte moderno de aspiraciones clasicistas - del binomio que formaban el crítico Eugenio d'Ors y el coleccionista Lluís Plandiura, ambos catalanes ${ }^{8}$. Es entonces, cuando el Manifiesto SAE revela las intenciones de aquéllos, cuando la SAE se desintegra por no compartir el resto de miembros esos postulados. La reacción de Eugenio d'Ors será publicar el libro Mi Salón de Otoño ${ }^{9}$, un gigantesco ensayo sobre algunas líneas de actuación que estaban ya presentes en ese Manifiesto SAE. De hecho, al comienzo de Mi Salón... aparece el texto completo de dicho Manifiesto:

«Tras de cincuenta años de anarquía, un anhelo ardiente agita hoy a los artistas del mundo. Con plena conciencia, los mejores, difusamente todos, aspiran a un restablecimiento del orden y a continuar, ahora austeramente y con una probidad perfecta, aquellas tradiciones más escogidas en que se ha cifrado en cualquier tiempo la esencia misma de la civilización... Tan rico en desengaños como en intentos, hoy el arte aprende a obedecer, sin mengua de las originalidades personales, a aquellas nuevas leyes, que son precisamente las leyes eternas. Aprende a buscar y a encontrar el secreto de la fuerza en el seno mismo de la norma. Forman ya una categoría muy importante los artistas españoles del día que [...] han venido a significar una continuación, acordada con la moderna sensibilidad, de la obra y la fe de sus mayores, honor de las famosas pinacotecas [...] Tanto como los artistas, sufre de la incomunicación el público [...] Para salvar la fatalidad de esta situación, para asegurar el triunfo de los nuevos ideales de orden y depuración artística, se constituye hoy en Madrid una Sociedad de Artistas Españoles... ${ }^{10}$.

Cuando en primavera de 1925 nazca la SAI, su primera actuación será publicar un Manifiesto fundacional, donde queden establecidos sus intereses y objetivos. Uno de los principales era resolver algunas deficiencias estructurales, como la ausencia de circuitos de exposición o la promoción del arte moderno que se realizaba en el interior peninsular. También completar el panorama del arte español contemporáneo, y para esto faltaban «los de fuera», los pintores y escultores españoles que trabajaban en el extranjero, sobre todo en París:

«Somos muchos los que venimos notando, con dolor, el hecho de que la capital española no pueda estar al tanto del movimiento plástico del mundo, ni aun de la propia nación en ocasiones, porque no se organizan en ella las Exposiciones de Arte necesarias para que conozca Madrid cuanto de interesante produce, fuera de aquí y aquí, el esfuerzo de los artistas de esta época [...] Toda actividad, en resumen, debe mantenerse en contacto permanente con la conciencia social, único término posible de contraste y referencia; única posibilidad, por lo tanto, de que hallen, tanto productores como espectadores, el complemento imprescindible para sus respectivas formaciones [...] procuraremos divulgar, por cuantos medios estén a nuestro alcance, no ya tal o cual tendencia sino toda posible tendencia y con más atención aquéllas que estén, de ordinario, menos atendidas y que sean indispensables para el cabal entendimiento de algún sector del arte viviente [...]» ${ }^{11}$.

Los firmantes del Manifiesto fundacional de la SAI son Manuel Abril, José Bergamín, Rafael Bergamín, Emiliano Barral, Francisco Durrio, Juan de Echevarría, Joaquín Enríquez, Oscar Esplá, Manuel de Falla, Federico García Lorca, Victorio Macho, Gabriel García Maroto, Cristóbal Ruiz, Adolfo Salazar, Ángel Sánchez Rivero, Joaquim Sunyer, Guillermo de Torre y Daniel Vázquez Díaz. Dos meses antes, a finales de marzo, se había publicado el mismo manifiesto pero en la nómina de firmantes había variaciones importantes, como la presencia del pintor catalán Ricard Canals o la ausencia de Rafael Bergamín y Guillermo de

8 Véase Brihuega, J.: «La ESAI y el arte español en la bisagra de 1925», La Sociedad de Artistas... op. cit., pp. 17-31.

${ }^{9}$ Ors, E. d'.: Mi Salón de Otoño, Madrid, supl. núm. 1, Revista de Occidente, 1924.

${ }_{10}$ Ibídem., pp. 4-5

"En los días posteriores, el Manifiesto fundacional de la SAI apareció publicado en numerosos medios de prensa: $H e$ raldo de Madrid, La Voz, Informaciones, Debate, Época, La Libertad, ABC y El Sol.

AEA, LXXVI, 2003, 302, pp. 177 a 185 
Torre ${ }^{12}$. Este último dato, el de la tardía incorporación de Guillermo de Torre, invalida cualquier hipótesis sobre su participación en la redacción del Manifiesto SAI, si bien durante la república será uno de sus principales animadores.

\section{Manifiestos y otros textos doctrinales de la SAI durante el lustro republicano}

Tras esa primera Exposición, la SAI agonizó en gran medida por la falta de apoyos económicos o institucionales, de modo que hubo que esperar a la proclamación de un nuevo régimen, la II República, para que renaciera la SAI, confiada en que las autoridades culturales republicanas le prestarían mayor atención. Así, en otoño de 1931 la SAI se dirige a la Junta de Relaciones Culturales, dependiente del Ministerio de Instrucción Pública y Bellas Artes, con la intención de materializar el que sería uno de sus objetivos centrales entre 1931 y 1936, el desembarco en Europa del arte español moderno y de vanguardia. Esa aspiración aparece ya recogida de forma extensa en un texto programático desconocido hasta ahora:

«La Sociedad de Artistas Ibéricos, que tiene como misión fundamental el dar a conocer en España las tendencias modernas que representan un valor vivo... se propone, ahora - recogiendo la atención que suscita fuera de España, su posible aportación al movimiento que, universalmente, está produciendo en arte también una honda transformación - organizar en el extranjero, con la cooperación de la Junta de Relaciones Culturales, una serie de exposiciones que den a conocer el arte español actual, ignorado rigurosamente la mayor parte de las veces» ${ }^{13}$.

Este texto debió parecer de gran interés a las autoridades culturales de la República, por lo que se solicita a la SAI una declaración de intenciones más detallada, que firman el 31 de octubre de 1931 el crítico de arte Manuel Abril y el arquitecto Luis Blanco Soler, quienes en esos momentos formaban todo el comité de la SAI:

«La Sociedad de Artistas Ibéricos quiere, al volver a constituirse en estos días, responder a una exigencia que, siendo vital para España y para la cultura del arte, no está representada ni atendida por ninguna agrupación de las que existen.

Sólo dos agrupaciones atienden en España el arte plástico: la Sociedad de Amigos del Arte y la Asociación de Pintores y Escultores. La primera consagra sus esfuerzos al arte del pasado y a manifestaciones más históricas que artísticas. La segunda no agrupa a sus socios por normas de arte y estética, sino pura y simplemente por motivos profesionales sin criterio selectivo; y por los nombres de la casi totalidad de sus adheridos, representa esta Asociación, dentro del arte en España, un arte tradicional de extrema y parcial derecha. Viven, pues, en España sin representación corporativa más de dos terceras partes de la producción española [...] nuestra Sociedad actúa porque existe una misión - la que ella quiere cumplir - fundamental y vitalísima, que está en la actualidad abandonada porque los demás no la cumplen [...].

Particularmente ahora nos dirigimos a Vds. por querer iniciar nuestra campaña de momento con un acto de importancia capital, que por igual enaltezca al arte español y a España. Nada, a nuestro juicio, para lograrlo como llevar a París, Londres, Berlín... una exposición coherente y ordenada de todo el arte español que vive y progresa en estos días acorde con las normas europeas.

Por 'normas europeas' entendemos aquello que, siendo de la historia del momento, pertenece además a las leyes de una ciencia estética eterna [...] Nosotros, pues, resumiendo, creemos poder representar toda una franja amplísima de arte, un vital movimiento de arte:

12 Alfar, La Coruña, núm. 1, VII-1925, p. 2.

13 Ministerio de Asuntos Exteriores, Caja 6289, Legajo 1736. 
$1^{\circ}$ Que es histórico; que no es caprichoso ni arbitrario.

$2^{\circ}$ Que es estético; que obedece a unas normas generales comunes a todos nosotros y que homogeneiza el grupo.

$3^{\circ}$ Que recoge y asume al formarse la representación de un número crecidísimo de artistas que tienen ya valor en todas partes» ${ }^{14}$.

El 14 de noviembre la Junta emite un documento en el que acuerda «prestar desde un principio el apoyo material y moral necesarios, condicionado a la presentación de un plan detallado de organización así como de la indicación de los artistas con que cuenten para llevarlo a cabo» ${ }^{15}$. Como se puede apreciar, la Junta y la República optaron en definitiva por la que era seguramente la solución menos complicada, esto es, patrocinar las actividades de una entidad que, como la SAI, se encargaría de todo lo demás, de la planificación, organización y puesta en práctica de sus propias exposiciones.

Como es lógico, el siguiente texto programático por parte de la SAI tampoco se hizo esperar (19-IX-1931), dada la importancia de lo que estaba en juego para la Sociedad: ser el organismo que representara por toda Europa al arte español moderno de la república. Por ello, los contenidos del texto se estructuran con claridad. En primer lugar, un cuerpo dispositivo inicial, donde se aclara lo que la SAI entiende por términos como arte, arte moderno, público y Estado español en relación con el resto de Europa:

«... La primera condición para que un arte pueda ser apreciado en todo su valor consiste en que todas sus obras obedezcan al mismo concepto estético, aunque luego, una a una, sean todas ellas tan diversas como diversas las personalidades que las creen. La homogeneidad estética entre las obras de una misma Exposición es, pues, condición imprescindible... El 'arte moderno' - tomado con la amplitud que damos a esta palabra - sólo considera dividido el campo del arte en dos grupos: uno, el arte 'plástico' por antonomasia; otro, el arte 'extraplástico' o arte de 'asunto'... Exponer, pues, los dos artes, en heterogénea mezcla, va en perjuicio o del uno o del otro. Más en perjuicio, desde luego, del arte plástico, puesto que la sensibilidad de la masa no sólo no está acostumbrada a enfocar el arte nuevo como debe, sino que tiene todo su automatismo psíquico hecho - por insistencia secular - a la polarización o enfoque opuesto.

Puede afirmarse, en reglas generales, que el público no ve nunca lo que hay en él de plástico, sino lo que hay de anécdota, o lo que hay de manual habilidad. Esa circunstancia se agrava al tratarse del arte moderno, porque el arte moderno prescinde casi siempre de ambas cosas: de la habilidad externa y de la anécdota [...] El arte en nombre del cual estamos hablando nosotros es un arte aceptado en todo el mundo [...] en la evolución del arte y de la estética, representa el movimiento de que hablamos el único que tiene condiciones - fundamento teórico y volumen- para hacer época en la Historia...» ${ }^{16}$.

En un segundo apartado del texto programático se detalla la división de los artistas españoles modernos y de vanguardia, con los nombres de los que van a exponer en la SAI en los años posteriores. Se trata de casi un centenar de artistas que configuran un paisaje muy preciso de nuestra vitalidad creativa:

«1. Precursores o pioneers: los que hace treinta años comenzaron a iniciar en nuestra patria los rumbos plásticos del arte. Regoyos, Echevarría, Iturrino, Durrio, Solana, Vázquez Díaz, Evaristo Valle, Arteta, Piñole, Pinazo, Cristóbal Ruiz, Macho, Mateo Hernández, Juan Cristóbal, Nonell, Vayreda, Mercadé, Canals, Sunyer, Aragay, Apa, Humbert, Mayol, Mir, Pidelaserra, Nogués, Gargallo, Manolo y Casanova.

\footnotetext{
${ }^{14}$ Ministerio de Asuntos Exteriores, Serie Ep E, Legajo R-746, Expediente 49.

15 Ibídem.,

16 Ibídem.,
} 
2. Los que constituyen actualmente la avanzada española en París. Picasso, Pruna, Juan Gris, Miró, Dalí, Bores, Cossío, Ismael González de la Serna, Peinado, Julio González y Gregorio Prieto».

3. Los que, residiendo aquí, fueron conquistando ya prestigio de nuevos maestros... ya sea por sanciones oficiales, ya por asenso de sectores representantivos de España. Pérez Rubio, Joaquín Valverde, Benjamín Palencia, Maruja Mallo, Moreno Villa, Pedro Sánchez, Genaro Lahuerta, Ponce de León, Souto, Castedo, Mateos, Climent, Ángeles Santos, Caviedes, Berdejo Elipe, Mompou, Francisco Domingo, Sunyer, Obiols, Serra, Sisquella, Vayreda, Marqués-Puig, Bosch-Roger, Cossío, Pelegrín, Balbuena, Servando del Pilar, Esteban Vicente, Frau, los escultores Ferrant, Alberto, Barral, Laviada, Díaz Bueno, Planes, Decref (sic), Pérez Mateo, Benet, Andreu, Rebull, Jurñac (sic), y los vascos Guezala, Bicandi, Ucelay, Tellaeche; por último, Almada y otros portugueses.

4. Los noveles; aquéllos que prometen y ensayan, siempre que en todos exista - por supuesto- un mínimo de valía que garantice esa calidad de 'promesa' de que hablamos. Esteban Vicente, Bonafé, Maortúa, Flores, Garay, Santonja, Esplandíu, Lorenzo Aguirre, Renau, Alvear, Rodríguez Luna, Isaías, Cristóbal, Suárez de Figueroa, Rosario de Velasco, Lola de la Vega, Marisa Pinazo, Marissa Röesset, Cabanas, Olasagasti, Acín, Díaz Yepes, Aladrén, Cristino Mallo y Tolosa» ${ }^{17}$.

Pocos meses después, la SAI logra hacer realidad el que había sido uno de sus objetivos prioritarios: la publicación de una revista propia en la que pudieran expresar, de manera periódica y destinada a todos los públicos, sus opiniones sobre el arte moderno. Se tituló Arte y produjo sólo dos números (septiembre 1932 y junio 1933) pero son un material indispensable para conocer el arte español de los primeros años treinta. En el núm. 1 aparece el Segundo Manifiesto de la SAI (el primero era el de 1925). Se trata de un extenso llamamiento de la Sociedad al Estado y al público españoles; además, por su dimensión y claridad expositiva, se convierte en uno de los textos que mejor describen la situación del arte español en tiempos de la república:

«Tenemos, ante todo, que hablar a la autoridad, porque ella es aquí tutor de todos, en lo que a las artes respecta. No hay, en la España de hoy, conciencia pública artística; la habría si existieran en España representaciones firmes, actuantes y conscientes, de todos los rumbos posibles, aunque después cada cual pensase como quisiera. ¿A quién culpar? No sabemos. En parte a la apatía de los ciudadanos todos; en parte, a los Gobiernos, que han estado manteniendo en todas las regiones oficiales cierta mezcla de abandono y partidismo, que persiste en este régimen $[\ldots]$

Sabemos, sí, perfectamente que no habrá salvación efectiva mientras cada cual, cada hombre, no sienta, por su parte, entre las necesidades apremiantes de su espíritu la necesidad del arte, la afición a fomentar la producción y compra de obras de arte; pero, dado que no existe esa afición en la medida o a la altura del nivel que corresponde a la actividad de un pueblo al día, compete a la autoridad - a nuestro juicio - acudir al remedio del colapso, asumiendo la inicial intervención, iniciando por su cuenta el Movimiento [...]

Por eso, sr. Ministro, esta instancia que a V.E. dirigimos no es solamente una súplica y un llamamiento, sino que es además una denuncia concreta. Quisiéramos que el sr. Ministro nos . pidiera — si duda de lo dicho por nosotros - responsabilidades y explicaciones de todo cuanto decimos:

Si es verdad que en España hubo exposiciones suficientes para haber tenido al día al público español, nosotros somos falsarios;

17 Ibídem.

AEA, LXXVI, 2003, 302, pp. 177 a 185 
Si es verdad que se hizo en este asunto todo cuanto se pudo, nosotros somos falsarios y levantamos falsos testimonios;

Si no es verdad que esos autores a los que nos referimos y ese movimiento de que hablamos ha sido ya acogido en todo el mundo culto y ha pasado a las revistas y Museos de todas las partes del mundo, exceptuados nosotros, que nos culpen porque estamos acusando falsamente.

Pero si es un hecho cierto lo afirmado, se nos debe atender, sr. Ministro, no ya como un simple grupo que se propusiera una labor - siempre loable — de noble y alta cultura, sino como algo más hondo: como una agrupación que aspira a nivelar y a establecer en lo posible la vida civilizada del arte en nuestra España...» ${ }^{18}$.

En comparación con uno de sus precedentes más inmediatos, como es el Manifiesto de la Agrupación Gremial de Artistas Plásticos (AGAP), publicado en diversos medios de prensa el 29 de abril de 1931, el manifiesto de la SAI utiliza un tono más explícito que aquél, está mejor informado de la realidad que vive el arte español contemporáneo y, en consecuencia, ofrece soluciones viables, no limitándose a describir la poco afortunada situación del arte ni a expresar en términos vagos la necesidad de un cambio urgente, como sucede en el manifiesto AGAP, en el que se extraen afirmaciones tan laxas como éstas:

«Lucharemos contra todo lo que signifique arbitrariedad y daremos en la medida que nos permitan nuestras fuerzas, un sentido amplio y renovador de la vida artística nacional, recabando los derechos que como clase nos corresponden» ${ }^{19}$.

Poco después del segundo Manifiesto, quizás sólo un par de semanas después, aparece un tercer Manifiesto, que se entregó a los interesados en dinamizar el arte y la cultura española:

«La Sociedad de Artistas Ibéricos, que hace años actuó fugazmente, se halla en la actualidad constituida de nuevo, cumplidos los requisitos de la ley y en vías de obra concreta: publicado el primer número de nuestra revista ARTE y a punto de inaugurarse en Copenhague nuestra primera Exposición de arte español fuera de España. No indica nuestro rótulo de Ibéricos ideología racial de ningún orden; alude solamente a la circunscripción peninsular de nuestra tierra.

Ideológicamente, nosotros estamos fuera de tendencias y de escuelas. Defendemos el arte moderno; pero no lo defendemos por «moderno» -lo «moderno», por sí solo, no tiene en arte sentido - sino por creer que ese arte contiene en sí, bajo apariencias multiformes y cambiantes, las leyes más eternas y más fundamentales de la estética.

En nuestra ideología caben todos los rumbos y los modos, salvo aquéllos en donde el arte se halla promiscuado con elementos ajenos que confunden y desvían y corrompen la auténtica orientación estética de las gentes, impidiéndoles que centren y dirijan su atención hacia lo intrínseco y profundo de las artes.

El «arte por el arte», la plástica por la plástica, ante todo, pudiera ser nuestro lema; pero entendiendo con ello, no la torre marfileña de hace años, en donde el artista quería dar de lado lo más hondo y entrañable de las cosas, sino queriendo recabar para las artes y para el concepto humano de la vida la creencia y la convicción de que el arte, en el sentido de que hablamos, concierne a la entraña misma del ser y del Universo. Pretendemos que la plástica profundiza mucho más cuando es solamente plástica que cuando se pone al servicio de otros fines, a los que no puede servir directamente, sino sólo de manera instrumental y, por ende, subordinada...

En la plástica, pues, sólo hay dos campos: aquel en donde el «asunto» asume la importancia primordial de la obra de arte y aquel en donde lo asume la plástica, pretendiendo ser ésta,

18 Anónimo: «Nuestro saludo y nuestros propósitos», Arte, Madrid, núm. 1, IX-1932, pp. 2-4

19 Anónimo: «Manifiesto de la Agrupación Gremial de Artistas Plásticos», El Sol, Madrid, 29-IV-1931. 
en esos casos, mucho más eficaz, más esencial, no ya para el arte mismo, sino para la íntima y recóndita identificación del hombre con las obras.

Perseguimos solamente - con asunto o sin asunto - la autenticidad del arte, por creer de limpieza y de eficacia que cada disciplina se mantenga en los límites que le incumben...

Como este arte, el intrínseco, no tiene entre nosotros representación corporativa, y como sin él queda manca la representación en España del arte universal - hoy vigente y acatado en todo el mundo- hemos fundado nosotros esta Sociedad para defender y propagar los derechos y el sentido de toda una mitad - por lo menos de una mitad - de la civilización estética de hoy día, mitad la más importante y la más fundamental; la más característica, además, del arte de nuestro tiempo. Para esa propaganda quisiéramos recurrir a todos los medios lícitos: revistas, exposiciones, cursillos, monografías: vulgarización y estudio. Estos son, pues, los principios de nuestra Sociedad, que quisiéramos también fuera la vuestra. Hemos retardado el momento de dirigirnos a todos a fin de poderles ofrecer, no proyectos y promesas, sino hechos. Ahora que los hay, que ya nuestra Sociedad representa una acción concreta, nos dirigimos a ustedes solicitando su adhesión, su atención, su ayuda y su consejo.

Por los escultores: Ángel Ferrant, Alberto, Manuel Laviada. Por los pintores: Vázquez Díaz, Pérez Rubio, Benjamín Palencia, Arturo Souto, Ponce de León, José Valverde. Por los arquitectos: Rafael Bergamín, Blanco Soler, Luis Moya, Sánchez Arcas. Por los músicos: Óscar Esplá, Salvador Bacarisse, Adolfo Salazar, Rodolfo Halfter. Por los escritores: Federico García Lorca, Antonio Marichalar, Guillermo de Torre, Jose María Marañón, Manuel Abril» ${ }^{20}$.

Como se menciona en el manifiesto, estaba a punto de inaugurarse la primera exposición de la SAI en el extranjero, en el Palacio Charlottenborg de Copenhague. El catálogo de dicha muestra era una ocasión magnífica para seguir desarrollando los contenidos teóricos de la Sociedad:

«... Suponemos que aquí, en Copenhague, lo mismo que allí, en España, lo mismo que en todas partes, habrá dos grupos distintos de personas: aquéllas que ven en el arte una ley universal y no creen que el arte y la belleza también necesitan recurrir a los 'bailes de trajes' nacionales, y otros para los cuales el arte sólo existe en estos espectáculos y creen que el patriotismo y la estética deben reducir el arte a una especie de propaganda de turismo... el arte es otra cosa, el arte verdadero no ve ni España ni el mundo, como un bazar brillante de razas y ceremonias. Ni desde el punto de vista estético ni desde el punto de vista español puede el arte aceptar la división del mundo en dos mitades: una de lujos y 'parques de atracciones', otra de prosaísmos indignos del arte. Para el arte no hay prosaísmos; para el arte no hay jerarquías de temas ni asuntos: todo es bueno; y en cuanto al españolismo en el arte y para el arte, lo español consiste en el modo de hablar y de decir las verdades universales, no en el empeño vano de conservar costumbres y modismos.

Aunque viste el español a la europea no deja de ser español quien lleva a España en la sangre. En arte, con más motivo ha de ocurrir otro tanto, puesto que el arte no es privativo de tal o cual nación sino que ha de hablar a todos los pueblos y ha de regirse por leyes que están por encima del tiempo y de las demarcaciones...» ${ }^{21}$.

Esa exposición se trasladó posteriormente a una de las grandes capitales europeas del arte contemporáneo, Berlín, donde se encargó de la muestra el prestigioso galerista Alfred Flechtheim ${ }^{22}$. El texto del catálogo es mucho más breve porque, como se afirma, en Alemania se

${ }^{20}$ El texto completo del tercer Manifiesto se puede leer en el catálogo Alberto 1895-1962, Madrid, MNCARS (itinerante), 2001 , p. 423 .

${ }^{21}$ Artistas Ibéricos. Exposición de Obras en Charlottenborg, Copenhague, IX-1932, pp. 7-9.

${ }_{22}$ Neuere Spanische Kunst, Gal. Flechtheim, Berlin, XII-1932/I-1933, pp. 3-6. Sobre el galerista alemán, el estudio más completo es el de Peters, H.: Alfred Flechtheim. Sammler, Hunsthändler, Verleger, Berlin, Editor, 1987.

AEA, LXXVI, 2003, 302, pp. 177 a 185 
sabía ya muy bien lo que era el arte de vanguardia, de manera que se reduce a una justificación de los artistas que habían sido seleccionados en tres grupos: la vanguardia (Picasso, Juan Gris, Miró, Dalí, Palencia, Pérez Rubio, Climent, Santa Cruz, La Serna), los más tradicionales o pioneros (Solana, Souto y Vázquez Díaz) y los españoles que realizaban obras en clave de Realismo mágico y Nueva Objetividad (Rosario de Velasco, Lahuerta, Pedro Sánchez, Pruna, Togores y Valverde).

A partir de 1933, la evolución política de España condicionó el devenir de la SAI, muy perjudicada por las elecciones de finales de ese año, que dieron paso a un Gobierno de derechas que retiró casi todo su apoyo a la Sociedad ${ }^{23}$. Con alguna actuación aislada, concluyen entonces sus años de mayor vitalidad - tanto en la celebración de exposiciones como en la redacción de manifiestos o textos doctrinales- con ese último gran acontecimiento que supone la exposición L'Art Espagnol Contemporain, celebrada en el Jeu de Paume parisino entre los meses de febrero y abril de 1936. Resulta muy significativo que en el catálogo ya no hay textos de miembros dirigentes de la SAI sino de Juan de la Encina, en calidad de Director del Museo de Arte Moderno, y del conocido hispanista francés Jean Cassou ${ }^{24}$. La Exposición de París fue la última aparición de la SAI, como temía uno de sus máximos responsables, Guillermo de Torre, en un artículo de mayo de 1936:

«La Sociedad de Artistas Ibéricos ha llegado a su clímax con la gran exposición recientemente celebrada en el Museo del Jeu de Paume, de París. Apoteosis y desmoronamiento - quizás - simultáneamente [...] la historia de la pintura libre en España es tan exigua que si omitiésemos los fastos de los Ibéricos quedaría reducida a nada [...] Si una sociedad de tipo libre no logra vivir en once años de la cooperación privada y necesita fatalmente apoyarse en el Estado, al no haber éste variado en materia de bellas artes córrese el riesgo de mediatizar y desnaturalizar aquélla. En estas condiciones y salvo que surja alguna otra perspectiva ¿merecerá prolongarse la existencia — por intermitente que sea— de la Sociedad de Artistas Ibéricos?» ${ }^{25}$.

Esta pregunta retórica sólo podía tener como respuesta una negativa. La SAI se disolvió de inmediato y, creo sinceramente, ni siquiera se puede buscar una razón o una excusa en el inminente estallido de la guerra civil. Con ella desaparecía una de las asociaciones más importantes de nuestra vanguardia histórica, tanto por sus planteamientos teóricos como por sus realizaciones en la práctica.

\footnotetext{
${ }^{23}$ Para un resumen de todas las actividades de la SAI en los años treinta, véase Lomba Serrano, C.: «El nuevo rostro de una vieja bandera: La Sociedad de Artistas Ibéricos en la República (1931-1936)», pp. 85-101.

${ }^{24}$ Encina, J. de la.: «Introduction» y CASSOU, J.: «Peinture espagnole», L'Art Espagnol Contemporain (Peinture et Sculpture), Paris, Musée des Écoles Étrangères, II-IV 1936, pp. 5-9.

${ }^{25}$ Torre, G. de.: «Anales de los Artistas Ibéricos», El Sol, Madrid, 27-V-1936.
} 